\title{
Vozes de Professores: \\ Indícios de/para Cursos de Formação
}

\author{
Teacher's Voices: Signs by/For Formation Courses
}

\author{
Jauranice Rodrigues CAVALCANTI * \\ Marina Célia MENDONÇA ** \\ Lilian BRANQUINHO $* * *$ \\ Rosana CARDOSO $* * * *$
}

Resumo: Neste artigo, analisamos discursos de professores sobre as práticas linguísticas de seus alunos e discursos de futuros professores. Partimos de estudos de Bakhtin sobre as vozes sociais em confronto e os valores ideológicos na produção de sentido. Resultados apontam para as seguintes conclusões: o aluno, nos discursos analisados, é mau falante, mau escritor, mau leitor; o grande vilão da linguagem e da leitura, na escola, é o advento de novas tecnologias e linguagens, que introduzem novas práticas ainda não aceitas pelos entrevistados. Nesses

\footnotetext{
* Doutorado e Pós-doutorado em Linguística. Mestrado em Letras. É professora do curso de Letras da Universidade Federal do Triângulo Mineiro. Contato: jrodriguescavalcanti@terra.com.br

** Doutora em Linguística pela UNICAMP (Campinas, SP/Brasil). Universidade Estadual Paulista "Júlio de Mesquita Filho" (UNESP), Departamento de Linguística, Faculdade de Ciências e Letras de Araraquara. Contato: marinamendonca@fclar.unesp.br

*** Mestre em Linguística pela Universidade de Franca (UNIFRAN) e Especialista em Língua Portuguesa e Literatura pela mesma universidade. Atualmente, leciona língua portuguesa e língua inglesa na rede estadual paulista. Contato: lilian.branquinho@bol.com.br

**** Mestranda em Linguística e Especialista em "Língua Portuguesa e Literatura: perspectivas teóricas de abordagem discursiva e textual" pela Universidade de Franca. Atualmente, é bolsista PROSUP/CAPES no Programa de PósGraduação em Linguística da Universidade de Franca. Contato: rosana.c.cardoso@hotmail.com
} 
discursos, vislumbram-se caminhos a serem percorridos em novos cursos para formação de professores.

Palavras-chave: Leitura. Escrita. Ensino.

Abstract: In this article we analyze discourses of teachers on the linguistic practices of their students and discourses of future teachers. We consider studies of Bakhtin on dialogism and ideology in the production of meanings. Results indicate the following conclusions: the student in the analyzed discourses is a bad speaker, a bad writer, a bad reader, the great villain of language and reading in school is the advent of new technologies and languages which introduce new practices that have not been accepted by the interviewees. In this discourses, we can notice ways that can be taken into consideration in new teacher's formation courses.

Key-words: Reading. Writing. Teaching.

\section{Introdução}

Este artigo apresenta resultados de pesquisa realizada no interior do projeto interinstitucional "Violência na/da escola", como parte dos trabalhos desenvolvidos pelo grupo de pesquisa Núcleo de Estudos em Análise do Discurso, certificado pelo CNPq. Nele, analisamos depoimentos de professores de escolas públicas do interior do estado de São Paulo e de futuros professores, alunos do curso de Pedagogia de uma faculdade também do interior desse estado. O tema central dos depoimentos são práticas de linguagem realizadas em sala de aula e os discursos dos professores foram obtidos a partir de aplicação de questionário escrito. A contribuição que pretendemos fazer é apontar indícios para redefinir práticas de formação de professores.

Partimos do pressuposto teórico de que os discursos sobre língua que são produzidos em contexto escolar sofrem um controle produzido pelo poder da ideologia e pela força da memória que movimenta o discurso escolar. Mas, nas brechas desses discursos, vislumbram-se movimentos na forma de significar a memória. Acreditamos que tanto o que se mantém em contexto escolar, quanto o que se desloca/move são relevantes e apontam para caminhos a serem percorridos em novos cursos de formação de professores. 
Ideologia e memória são aqui pensadas na perspectiva de Bakhtin (2000) e Bakhtin/Volochínov (1988). Refletindo sobre valores ideológicos que constituem o horizonte de expectativa de determinados grupos sociais, Bakhtin/Volochínov (1988) chama a atenção para o processo em que se dá a produção de sentido: esta, segundo o filósofo, está apoiada não somente na estabilidade da significação da língua, em sua relativa fixação ao longo da história, mas também no acontecimento a que o autor chama de tema, que dá ao enunciado o caráter individual e único. Este é condicionado pelas relações interativas imediatas e também pelas relações sociais mais amplas, pelo horizonte apreciativo do grupo social em que se dá a interação: “[...] a significação objetiva forma-se graças à apreciação; ela indica que uma determinada significação objetiva entrou no horizonte dos interlocutores - tanto no horizonte imediato como no horizonte social mais amplo de um dado grupo social.” (BAKHTIN/VOLOCHÍNOV, 1988, p. 135). É devido ao tema, tomado nessa perspectiva, que a significação se renova continuamente, no acontecimento/evento, em que ocorre um diálogo que atualiza a "memória do passado" e avança a compreensão responsiva do outro/destinatário. Esse diálogo com o porvir do discurso o autor chama de memória do futuro.

O enunciado verbal, nessa perspectiva de Bakhtin (2000), faz parte de um evento concreto de uso linguístico, e ele se constitui como resposta a outros enunciados, no diálogo com as vozes sociais que o precedem, mas também com o destinatário imediato e com o superdestinatário que constitui o horizonte de expectativas daquele que enuncia. Essas vozes dos destinatários do enunciado podem ser:

[...] o conjunto diferenciado de especialistas em alguma área especializada da comunicação cultural, pode ser o auditório diferenciado dos contemporâneos, dos partidários, dos adversários e inimigos, dos subalternos, dos chefes, dos inferiores, dos superiores, dos próximos, dos estranhos, etc. (BAKHTIN, 2000, p. 320)

Dessa forma, o diálogo em Bakhtin compreende a grande e a "pequena" (mas não insignificante) temporalidade. 
É relevante ainda destacar, neste artigo, que enunciar, nessa perspectiva dialógica, é responder à enunciação do outro com contrapalavras. De acordo com essa perspectiva, a produção linguística é um processo sempre aberto, rico em diversidade, mas que não descarta sentidos em circulação na sociedade, na história, não descarta a estabilidade provisória da significação (GERALDI, 1993).

Esses apontamentos balizam o espaço teórico em que se localiza esta reflexão. É com base neles que interpretamos as respostas dos professores e dos alunos-futuros professores à memória que os constitui. Essa memória, estabilizada historicamente e presente no senso comum, estabelece relativamente (já que sofre influência do evento de linguagem) a não aceitação de variedades linguísticas, a não autorização de modos de dizer/ler, as quais criam uma política do dizer/ler em uma rede de controle em sala de aula.

Ademais, buscamos no corpus (que se constitui de depoimentos de professores e de futuros professores) uma representação do sujeito aluno em sua relação com a linguagem, com a leitura e a escrita. Interessanos analisar em que medida essa representação, no diálogo com a memória discursiva, atualiza discursos que ajudam a lhe produzir uma identidade.

\section{Apontamentos sobre a relação entre discurso, senso comum e memória}

Em estudo anterior (MENDONÇA, 2007), destacamos que o senso comum sobre a linguagem tem sido apontado por linguistas brasileiros, nas últimas décadas, como conservador (indo ao encontro das concepções linguísticas presentes nas gramáticas tradicionais) e preconceituoso em relação às variedades não cultas e/ou variedades de regiões pouco prestigiadas e em relação a algumas formas novas na língua portuguesa do Brasil ou a características do português brasileiro.

Castilho (1988) lista alguns desses preconceitos presentes em falas de professores, dentre eles o de que a norma culta representa o português correto, que tudo o que foge à norma representa um erro. $\mathrm{O}$ autor avalia essas posições sobre a língua portuguesa e suas variedades como "desinteligências", "confusões" ou "enganos". Tais preconceitos também são tratados por linguistas como "mitos" que 
devem ser combatidos. Bagno (2001), por exemplo, toma por "obscurantismo anticientífico" a forma como a mídia considera a língua. Além disso, contrapondo os estudos científicos aos produzidos pelo senso comum, o autor afirma que:

Quando o assunto é língua, existem na sociedade duas ordens de discurso que se contrapõem: (1) o discurso científico, embasado nas teorias da Lingüística moderna, que trabalha com as noções de variação e mudança; e (2) o discurso do senso comum, impregnado de concepç̃oes arcaicas sobre a linguagem e de preconceitos sociais fortemente arraigados, que opera com a noção de erro. (BAGNO, 2006 grifos nossos)

O senso comum sobre língua é tratado pelo linguista como "arcaico" e impregnado de preconceitos sociais. Considerando, com Bagno, que esse senso comum está presente na história brasileira (ver Mendonça, 2006), podemos afirmar que encontramos nele "um purismo linguístico que busca a preservação do idioma em sua qualidade de 'bem dizer"'. É nesse sentido que se pode afirmar que o senso comum sobre língua é conservador, visto mostrar rejeição a inovações linguísticas e a variedades.

Consideramos formas de saberes os chamados mitos constituintes do discurso do senso comum (MENDONÇA, 2007). Esses saberes são institucionalmente constituídos pelas práticas discursivas midiáticas, pelo sistema de distribuição do conhecimento - publicações de gramáticas e de manuais do "bom uso da língua" -, pelas práticas escolares que perpetuam a tradição gramatical. (BRITTO, 1997; MENDONÇA, 2006) Entretanto, eles encontram resistência no discurso da Linguística, que com eles mantém um diálogo tenso e contínuo, principalmente a partir da década de 1970, no Brasil. O efeito desse diálogo na materialidade do discurso sobre língua que circula em diversas esferas, entre elas a de comunicação e a pedagógica, é a ressignificação do discurso da ciência realizada pelo discurso purista (discurso do saber do senso comum); aquele, de descritivo ou explicativo, passa a prescritivo - trata-se, nesse caso, de uma mudança da função e do tom do discurso. (MENDONÇA, 2007) Entendemos que essa passagem da descrição/explicação para a prescrição é mola 
para as atitudes de intolerância em contexto escolar. Essa passagem produz a relevância do certo versus o errado, do bom versus o ruim, do aceitável versus o inaceitável. Nas práticas pedagógicas, que ocorrem em espaço institucional em que as hierarquias reservam aos sujeitos espaços dos quais se podem enunciar determinados discursos e outros não, vozes autorizadas atualizam critérios de qualidade de discursos, atualizam os valores ideológicos dominantes no contexto em que se dão. O que é aceitável no discurso condiz com os valores ideológicos presentes nas práticas sociais da elite cultural do país.

Para as reflexões que nos propomos desenvolver aqui, ainda é preciso fazer algumas considerações acerca do senso comum sobre a produção de sentido, que interfere, em nossa hipótese, na concepção de leitura em contexto escolar. Zabalar (2009), em análise do discurso sobre a leitura presente na revista Nova Escola, faz um levantamento bibliográfico sobre o tema da leitura no Brasil em contexto científico (ou seja, recupera parte dos discursos presentes na nossa memória discursiva) e analisa a (res)significação dessa memória no/pelo periódico. Considerando-se que se trata de veículo de grande circulação nacional e com grande presença nas relações de ensino no Brasil, acreditamos poder definir que aquilo que nele se encontra constitua parte do que vem sendo tomado como senso comum sobre leitura, inclusive porque, como pontua a autora, o discurso da revista atualiza alguns aspectos sobre a competência leitora tal como propostos nos Parâmetros Curriculares Nacionais de Língua Portuguesa, documentos que vêm influenciando o ensino de língua no país.

Segundo Zabalar (2009), a leitura é representada na revista analisada como uma atividade ao mesmo tempo solitária e interativa. Além disso, proporciona uma "viagem" àqueles que a praticam - ou seja, amplia-lhes os horizontes, permite-lhes o acesso a outras realidades etc. Outra característica que a leitura assume na revista em questão é a de redimir os sujeitos da miséria econômica e social - nesse sentido, é mitificada. Há poucas referências ao caráter sócio-histórico da leitura, às formas diferentes de produzir sentidos em função das condições de produção e recepção. Para a pesquisadora, a revista em questão não considera a leitura como espaço de construção de sentidos, como uma atividade complexa que envolve uma série de habilidades. Outro aspecto a ser destacado no estudo da autora é que o periódico toma 
seu destinatário presumido (o professor?) como um mau leitor, da mesma forma como, em gêneros como o "plano de aula", trata como mau leitor o aluno (no caso, esse gênero atualiza o discurso didático em sua abordagem da atividade de leitura, segundo pesquisa por nós desenvolvida em Mendonça, 1995).

\section{A voz do senso comum sobre língua (escrita) no discurso de professores}

Em pesquisa realizada com professores, coletaram-se depoimentos/opiniões sobre a linguagem oral e escrita de alunos da escola básica. O procedimento metodológico utilizado foi aplicação de questionário dirigido a professores de 40 a 55 anos de idade, docentes de escolas públicas do interior do estado de São Paulo. Todos os que responderam às perguntas estão há mais de dezesseis anos no magistério.

O questionário respondido apresentava duas questões. São elas:

1) Como você analisa a linguagem dos textos escritos de seus alunos?

2) O que você acha da linguagem oral? Justifique.

Selecionamos as respostas de quatro professores: um de Ciências (com vinte e três anos de magistério), dois de História (um com vinte anos de magistério, outro com vinte e três) e um de Matemática (com aproximadamente dezesseis anos de magistério). A seguir, as respostas de um professor de História e de um de Ciências à primeira questão, respectivamente: ${ }^{1}$

Entrevista 1 - São péssimos, de difícil interpretação, sem coesão, coerência, muitos erros ortográficos, pontuação.

Entrevista 2 - Trabalhando somente com os alunos do ensino fundamental II, percebo que eles apresentam grande dificuldade nas produções de texto. Os textos não possuem coerência, sinais de pontuação e apresentam bastante erros ortográficos.

\footnotetext{
${ }^{1}$ Neste artigo, não fizemos alterações no texto escrito pelos professores e alunosfuturos professores.
} 
Os professores, mesmo não sendo da área de Letras e Linguística, conhecem os conceitos de coesão e coerência (pelo menos os enuncia), desenvolvidos pela Linguística Textual, o que indicia que esses já são considerados como traços indicadores da qualidade textual entre docentes de diversas áreas. Nas entrevistas, atribuem-se valores negativos aos textos produzidos pelos alunos. A avaliação do texto escrito, no discurso dos professores, toma por critério, além dos aspectos textuais/discursivos, a correção ortográfica.

Vejamos dois professores de História respondem à pergunta relacionada à linguagem oral dos alunos:

Entrevista 1 - A linguagem deles é um pouco melhor que a escrita, porém com muitos vícios de internet e o dia a dia que usam uma linguagem popular. Poderiam melhorar mais, através de diversos tipos de leitura.

Entrevista 4 - A linguagem oral está ligada ao mundo da informática, onde eles estão falando como se estivesse na tela de um computador.

A Entrevista 1 dialoga de forma convergente com o discurso purista (com o saber do senso comum, que é conservador e desqualifica as inovações e variedades linguísticas), em que se toma a "linguagem popular" como um desvio presente na fala, não a considerando como uma variante legítima do português. $\mathrm{O}$ contexto no qual ocorrem as falas, os participantes envolvidos nas interações, nada disso é considerado.

Em contraposição ao discurso purista, que constitui parte do senso comum sobre língua, circula, na sociedade brasileira, o discurso da ciência da linguagem. Dessa esfera de comunicação científica, enuncia-se, como vimos, contra a identificação entre variação e erro linguístico. Esse discurso científico fez parte da realidade escolar, em forma de publicação distribuída às escolas públicas do estado de São Paulo, por exemplo, em texto de Castilho (1988, p. 54): “não há português certo ou errado e sim modalidades de prestígio e modalidades desprestigiadas".

Nessas entrevistas, percebemos formas de ressignificação, em falas de professores, do discurso da Linguística, quando da recuperação 
da memória - o discurso da valorização de aspectos como coesão e coerência convive com a permanência do purismo linguístico.

Outro aspecto a ser destacado, nas entrevistas, é a valoração negativa que os docentes fazem da linguagem da internet. Nesses casos, o vilão da linguagem oral, por paradoxal que seja, é a "linguagem da informática" - caso o professor esteja se referindo ao chamado internetês, há não somente preconceito com essa variedade da língua escrita, mas também incompreensão do fato de que ela só se manifesta na modalidade escrita e não poderia influenciar diretamente a fala dos seus usuários.

Vejamos agora como o professor de Ciências posiciona-se em relação à segunda questão:

Entrevista 2 - Um pouco melhor que a linguagem escrita, porém, diante de questionamentos os alunos possuem uma argumentação restrita, ou seja, respostas simples e nem sempre explícitas.

Podemos dizer que a fala desse professor não é menos preconceituosa que as anteriores, já que afirma que os discentes possuem uma argumentação simples em seu texto falado, ou seja, pouco elaborada (isso significaria um pensamento pouco elaborado?). Sabemos que a ideia de que haveria relação entre linguagem restrita e pensamento "pobre" foi defendida antes das pesquisas e contribuições da Sociolinguística. Trata-se do que Soares (1986) chama de ideologia da deficiência cultural, que culpa o grupo social do aluno por seu "fracasso" escolar: haveria uma pobreza cultural (envolvendo afetividade, capacidade cognitiva e linguística) nas classes populares que impediria que seus integrantes estivessem aptos para a aprendizagem. Considerando que esse ponto de vista teve larga influência nas relações de ensino de língua no Brasil, podemos inferir que o professor recupera essa memória em seu discurso.

Percebemos também que o docente concebe o texto falado segundo os parâmetros do escrito, o que tem sido apontado por linguistas como uma atitude, no mínimo, inadequada em relação à fala (MARCUSCHI, 2001). Veja-se que o professor espera, na fala do aluno, uma explicitude que é mais encontrada na modalidade escrita das línguas. Novamente, indicia-se, no discurso do professor, que este desconhece aspectos básicos relativos à oralidade/letramento. 
Uma hipótese explicativa para a permanência de preconceitos linguísticos no discurso dos professores entrevistados é a de que não somente eles não são da área de Letras e Linguística, mas também passaram pelo curso universitário antes do período em que as pesquisas da sociolinguística e de aspectos relativos ao letramento contribuíram para a alteração das relações de ensino. Nesse sentido, o discurso dos docentes constituir-se-ia prioritariamente na relação com a memória do discurso das gramáticas tradicionais, que priorizam o estudo do padrão culto e escrito da língua, o qual é modelo para todas as atividades de linguagem. Outra hipótese explicativa é a força da memória ao longo da história, na grande temporalidade tal qual a entende Bakhtin (2000).

As respostas dos professores ao questionário também nos levam a outra indagação: o fato de os professores já apresentarem, em suas respostas, interferências do discurso da Linguística Textual sugere que um novo conceito de textualidade estaria se firmando nas práticas escolares. Entretanto, não se pode esquecer que os conceitos de coesão e coerência, presentes nas falas dos professores entrevistados, circulam hoje no discurso pedagógico, mas sem muita precisão ou mesmo entendimento sobre o que seriam e/ou como poderiam ser reconhecidos nos textos produzidos pelos alunos. Observamos (CAVALCANTI, 2006), fundamentadas no convívio com professores em cursos de formação, que os conceitos de coesão e coerência foram transformados em "fórmulas", isto é, são muito repetidos, mas deles pouco se sabe, inclusive como torná-los produtivos no ensino da escrita e na avaliação da produção textual dos alunos.

\section{O aluno na voz do professor - a representação do mau leitor}

Neste item, nosso objetivo é analisar o discurso sobre as habilidades de leitura enunciado por professores de língua portuguesa e outras disciplinas da rede pública do interior do estado de São Paulo, no sentido de encontrar, nesses discursos, indícios para caminhos a serem percorridos em cursos de formação. Aqui, apresentamos uma pesquisa realizada com doze professores de uma escola estadual. Tratase da aplicação de um questionário no qual incluíam-se as perguntas abaixo: 
1) Você considera o seu aluno um bom leitor? Justifique sua resposta;

2) Faça uma autoavaliação considerando a sua relação com a leitura. Você pode centrar sua autoavaliação, se quiser, em alguma das seguintes questões: Você lê bastante? Entende o que lê? Acha difícil o que lê? O que você gosta de ler?

$\mathrm{Na}$ análise das respostas à primeira questão, verificamos que grande parte dos professores não acredita nas habilidades de leitura de seus alunos - considera que são maus leitores. Essa avaliação é percebida principalmente na fala dos professores de Língua Portuguesa e Língua Inglesa. Abaixo, citamos alguns fragmentos das respostas à questão 1:

- Grande parte dos alunos não são bons leitores [...]. (Professor de Língua Portuguesa, Projeto Leitura e PD, entrevista 5);

- Não, pois meus alunos não tem o hábito de leitura prazerosa. (Professor de Língua Portuguesa, entrevista 6);

- Acredito que esta é a busca principal dos professores e da educação no Brasil. (Professor de Inglês, entrevista 7);

- Não. Infelizmente nos dias atuais a maioria dos alunos não lê [...] (Professor de Língua Portuguesa e Geografia, entrevista 8); - Não, os alunos de hoje em dia, não gostam de ler [...] (Professor de Língua Portuguesa e Literatura, entrevista 9).

Já os professores de outras disciplinas, como Educação Física, Matemática e Ciências, demonstraram outra atitude ao serem questionados se consideram seus alunos bons leitores. Esses docentes relativizaram a resposta, incluindo a existência do leitor proficiente em contexto escolar quando em práticas efetivas de leitura (como em um jogo e/ou na compreensão do conteúdo da matéria dada). Vejamos os dados a seguir:

- No entanto quando essa interpretação se dá de forma mais concreta, análise de uma atividade (jogo) feita por eles, por exemplo, a grande maioria demonstra maior entendimento em aspectos mais profundos. (Professor de Educação Física, entrevista 1); 
- [...] há alunos que têm capacidade de interpretação. (Professor de Ciências, entrevista 10);

- Geralmente são aqueles alunos que tem mais facilidade de entender a matéria (a minha matemática). (Professor de Matemática, entrevista 11)

O discurso do "mau leitor", como visto na seção 1, está presente no senso comum sobre a capacidade de leitura do brasileiro. Como os saberes proverbiais, o saber do senso comum ganha força em sua atualização contínua, o que lhe confere valor de verdade. Entretanto, verifica-se um movimento de reação no discurso de professores de outras disciplinas (um dado surpreendente, já que o professor de línguas é o que tem acesso, em sua formação, a teorias sobre leitura, desde as que têm por objeto de estudo o texto literário até as teorias linguísticas que se seguiram ao desenvolvimento da Semântica).

É interessante destacar que os docentes apontam a tecnologia e a família como causas de os alunos serem maus leitores, de a leitura não ser algo prazeroso, de não ser um "hábito". Assim, eles não consideram a internet, o videogame, a televisão, por exemplo, como fontes/materiais de leitura. Consideram leitura apenas aquela que se realiza na interação com textos impressos, não valorizando outras formas de linguagens além daquela que veicula a modalidade escrita no suporte de texto livro ou outro material impresso. O trecho a seguir exemplifica essa posição - trata-se de resposta à primeira questão:

- Não, os alunos de hoje em dia, não gostam de ler pois devido ao avanço tecnológico, nossos estudantes não se interessam muito pela leitura. Também devido a falta de incentivo de seus familiares, eles preferem assistir televisão, internet e vídeo-games. (Professor de Língua Portuguesa e Literatura, entrevista 9)

O discurso que emerge das respostas dos professores que participaram desta pesquisa dialoga de forma convergente com o discurso de professores analisado na seção anterior: o desenvolvimento tecnológico (no caso, a linguagem da internet) é fator que interfere negativamente na linguagem dos alunos e em sua capacidade de leitura. 


\section{A voz do aluno-futuro professor sobre si}

Neste item, apresentamos trechos de textos produzidos por alunos do primeiro ano de Pedagogia de uma faculdade particular do interior de São Paulo. São fragmentos de textos produzidos no gênero memorial, no qual os futuros professores relatam as experiências sobre leitura e escrita no contexto escolar de que se recordavam. Transcrevemos alguns depoimentos:

1. Escrevi realmente muito pouco, mais o bastante para saber que não o fazia bem; meus professores diziam me em relação à criatividade você é ótima é quase que insuperável mais deixa a desejar em relação à escrita (A.L.C.).

2. Só a partir da quinta série, com professores diferentes que comecei a tirar um pouco da defasagem na escrita. Minha memória sempre me mostra o quanto queria aprender a suprir o que faltava e sempre houvia que agora é tarde corra você atrás do prejuízo. E até hoje continuo correndo atrás de escrever melhor, aprender escrever com coesão e entender o que se pede (M.C.D.).

3. Fiz várias redações durante meus estudos, mas até hoje não sei se escrevi o que a professora tinha pedido ou se estava relacionado com o tema posto. Só sei que apartir de 2003 venho lendo vários livros, literatura, romance, revistas, entre outros, mas o maior problema ainda não consegui resolver da minha formação. Interpretar um texto, escrever o que o texto ou a pergunta quer que eu responda. Minhas redações foram só palavras sem sentido e sem aprendizagem (M.S.)

Os depoimentos desvelam concepções de escrita arraigadas e que entram no processo de ensino-aprendizagem. A primeira delas, presente na fala 1 , diz respeito à noção de criatividade, tão empregada no contexto escolar, tão imprecisa. Remete à ideia de que seria possível separar o processo de escrita em dois planos distintos: o seu "conteúdo" e a sua "forma". A aluna, muito provavelmente, ouviu 
que pecava na forma, não a dominava, embora fosse "criativa", rica em ideias, no conteúdo.

No depoimento 2, como no anterior, também aparece retomada uma fala ouvida pela aluna, a voz do professor, ainda tão presente (constitutiva) na memória: "agora é tarde corra você atrás do prejuízo". Infelizmente, não é incomum alunos chegarem não alfabetizados às últimas séries do ensino fundamental. Esse "fenômeno" tem levado algumas secretarias de educação a oferecerem cursos de alfabetização aos professores dessas séries, que se dizem despreparados para resolver um problema que consideram não ser deles. Isso talvez explique a voz que insiste em continuar ressoando, uma voz que veicula o ponto de vista de que haveria um "período crítico" para aprender a leitura/ escrita, que depois dele nada mais poderia ser feito pelo professor (a aluna que teria de resolver sozinha).

No último enunciado, "e até hoje continuo correndo atrás de escrever melhor, aprender escrever com coesão e entender o que se pede”, pode-se perceber outra intromissão, outra voz. A aluna parece referir-se a observações que tem ouvido ('um texto deve ter coesão e coerência', os conceitos que se tornaram fórmulas), a leituras que vem sendo solicitada a fazer, leituras distantes da(s) sua(s) ("entender o que se pede").

Embora as aulas de português tenham, nos últimos anos, acolhido diferentes textos, de diferentes gêneros, para fazer deles objeto de estudo, essa apropriação, como bem mostra o depoimento acima, ainda não abre espaço para reflexões, para ouvir as contrapalavras do leitor ou analisar as estratégias usadas para construir o projeto de texto do autor. As atividades acabam reduzidas a verificar o que o texto diz (seu conteúdo) ou mesmo o que "o autor quis dizer".

No depoimento 3, a aluna reflete sobre os textos que escreveu ("várias redações"), avaliando-os como "palavras sem sentido e sem aprendizagem". Essa avaliação explica-se, provavelmente, pelas dificuldades que deve enfrentar quando da interpretação de textos: "escrever o que o texto ou a pergunta quer que eu responda". Assim como no depoimento anterior, nota-se que o trabalho com textos, tanto no período que recorda como no atual, silencia a sua voz: aquele por não dar oportunidades para construir seu dizer (conhecer outros pontos de vista, outros modos de dizer), este por oferecer o texto como já acabado, à espera das "respostas certas", da "interpretação". 
Em nenhum momento, a voz cogita que o "erro" esteja em outro lugar além/fora dela, na possibilidade de a professora não ter sido/ser uma boa leitora de seus textos (ou sequer os tenha lido), na possibilidade de não ter tido espaço/condições de constituir-se como a leitora que a escola esperava que ela fosse. Assume que cabe somente a ela "correr atrás do prejuízo", ler bastante, escrever muito (provavelmente o que lhe apontam como solução).

Os trechos analisados indiciam que a representação de "mau leitor" e de "aquele que escreve mal e de forma confusa" é internalizada pelos alunos futuros-professores no diálogo com a memória. São sentidos que circulam em nossa formação social, uma memória sobre o saber linguístico do aluno, que pode ser apreendida também na fala de alunos-futuros professores; sentidos que constituirão, sem dúvida, a identidade das futuras docentes.

\section{Considerações finais}

Vimos, neste artigo, indícios de controle do dizer/ler do aluno presentes no discurso de professores e também de alunos-futuros professores. Entre as características linguísticas destacadas como ruins nos textos escritos e orais dos alunos, encontram-se problemas de ortografia, de falta de concordância, de falta de coesão e coerência e de interferências do internetês. Em relação à leitura, coloca-se genericamente o aluno como um mau leitor, sujeito que deve ser exposto a atividades que visem a desenvolver suas habilidades leitoras - entre elas, a formação do "hábito" de leitura.

Segundo os entrevistados, o grande vilão da linguagem e da leitura na escola é o advento de novas tecnologias e linguagens, que introduzem novas práticas ainda não aceitas, que devem ficar distantes das relações de ensino. Nesse sentido, a escola continua espaço que suprime de suas fileiras a "língua viva" - a linguagem do dia a dia, o dialeto dos alunos, a linguagem da internet, as leituras que interessam aos alunos.

Quando representados pela voz dos professores (que, nesse momento, atualizam as vozes conservadoras e excludentes que circulam no horizonte social de nossa sociedade atual), os alunos emergem como sujeitos de linguagem pobre, incorreta, inadequada; como sujeitos de 
pouca e irrelevante leitura. As identidades que emergem dos depoimentos analisados atualizam ideologias que constituem a memória em que se sustenta o discurso dos professores - seja a memória do purismo linguístico reforçada pela mídia, seja a memória do mau leitor que constitui o senso comum sobre leitura no Brasil.

Entretanto, nas margens desse discurso conservador, vislumbram-se movimentos, no contrafluxo, no conflito ideológico que constitui os nossos sujeitos entrevistados: o texto já é tomado como objeto que deve produzir sentido, e a leitura, na fala de professores não formados nos cursos de Letras, é atividade que seus alunos praticam, por vezes, de forma adequada.

Esses resultados apontam para conteúdos e práticas que, por certo, podem ser abordados em cursos de formação de professores.

\section{Referências}

BAKHTIN/VOLOCHINOV. Marxismo e filosofia da linguagem. Trad. Michel Lahud; Yara F. Vieira. 4. ed. São Paulo: Hucitec, 1988.

BAKHTIN, M. Estética da criação verbal. 3. ed. São Paulo: Martins Fontes, 2000.

BAGNO, Marcos. Preconceito linguístico: o que é, como se faz. São Paulo: Loyola, 2001.

- Nada na língua é por acaso: ciência e senso comum na educação em língua materna. 2006. Disponível em: http:// www.marcosbagno.com.br/art_nada-na-lingua-e-poracaso.htm. Acesso em: 3 jun. 2007.

BRITTO, Luiz Percival L. A sombra do caos: ensino de língua x tradição gramatical. Campinas: ALB/Mercado de Letras, 1997.

CASTILHO, Ataliba T. de. Variação linguística, norma culta e ensino da língua materna. In: SÃO PAULO. Secretaria de Educação do Estado de São Paulo. Subsídios à proposta curricular de Lingua Portuguesa para 1. e 2. graus. São Paulo: SE/CENP, 1988. v.1. 
CAVALCANTI, Jauranice R. A formação de professores autores. Projeto de pós-doutoramento. Campinas: IEL/UNICAMP, 2006.

GERALDI, João Wanderley. Portos de passagem. 2. ed. São Paulo: Martins Fontes,1993.

MARCUSCHI, L. A. Da fala para a escrita: atividades de retextualização. São Paulo: Cortez, 2001.

MENDONÇA, Marina Célia. Silenciamentos produzidos em questões de leitura. 1995. Dissertação (Mestrado em Linguística) - Universidade Estadual de Campinas, Campinas. 1995.

- A luta pelo direito de dizer a língua: a lingüística e o purismo lingüístico na passagem do século XX para o século XXI. 2006. Tese (Doutorado em Linguística) - Universidade Estadual de Campinas, Campinas. 2006.

- O senso comum sobre língua: notas sobre um discurso marcado pelo outro. In: CARMELINO, A.C.; PERNAMBUCO, J.; FERRREIRA, L.A. (Orgs.) Nos caminhos do texto: atos de leitura. Franca: Editora da Unifran, 2007.

SOARES, Magda. Linguagem e escola: uma perspectiva social. São Paulo: Ática, 1986.

ZABALAR, Débora M. A leitura na revista Nova Escola: dialogismo e produção de sentido. 2009. Dissertação (Mestrado em Linguística) Universidade de Franca, Franca. 2009. 